10. Yogev R, Shulman D, Shulman ST, Glogowski WG. In vitro activity of antibiotics alone and in combination against Actinobacillus actinomycetemcomitans. Antimicrob Agents Chemother 1996; 29: 179-81.

11. Babinchack TJ. Oral ciprofloxacin for prosthetic valve endocarditis due to Actinobacillus actinomycetemcomitans. Clin Infect Dis 1995; 21: 1517-8.

\section{Meningitis aguda por Streptococcus suis: a propósito de un caso en un paciente esplenectomizado}

\section{Sr. Director:}

La infección por Streptococcus suis es una zoonosis con un riesgo ocupacional, especialmente en individuos en contacto cerrado con cerdos (1). La manifestación clínica más frecuente es la meningitis aguda (2-4). Se han descrito pocos casos de infección por $S$. suis, procedentes en su mayoría de Holanda y cols. países del norte de Europa, Hong Kong, Singapur y otras zonas del Extremo Oriente. En España se han publicado hasta la fecha cinco casos de meningitis por $\mathrm{S}$. suis, todos ellos afectando a individuos inmunocompetentes $(1,5,6)$. Aportamos un nuevo caso de meningitis por este patógeno en un paciente esplenectomizado.

Caso clínico: Varón de 29 años con antecedentes de esplenectomía por rotura de bazo traumática cinco años antes del episodio actual. Trabajaba en la recogida de desechos cárnicos. Una semana antes de su ingreso presentó un cuadro compatible con una gastroenteritis aguda. En las últimas 48 horas se añadió fiebre y cefalea. La exploración inicial evidenció rigidez nucal y signos meníngeos, siendo el nivel de conciencia y el resto del examen clínico normales. La analítica sanguínea puso de manifiesto leucocitosis $\left(47.000 / \mathrm{mm}^{3}\right)$ con neutrofilia. En la punción lumbar se obtuvo un líquido cefalorraquídeo turbio, ligeramente hipertenso, con 12.000 leucocitos $/ \mathrm{mm}^{3}$ (98\% polimorfonucleares), hipoglucorraquia e hiperproteinorraquia. En la tinción Gram aparecieron cocos gram-positivos en cadenas cortas, que hacían sospechar en primera instancia una infección por Streptococcus pneumoniae. Se inició tratamiento con ceftriaxona y vancomicina. La TC cerebral fue normal. En las siguientes horas el nivel de conciencia se deterioró y fue necesaria la ventilación mecánica. Desarrolló un estatus convulsivo generalizado. La respuesta al tratamiento convencional de estas complicaciones fue favorable y a las 48 horas pudo ser extubado sin incidencias. La resonancia magnética encefálica no mostró hallazgos de interés.

El Servicio de Microbiología informó del crecimiento, tanto en LCR como en los hemocultivos, de cocos grampositivos en cadenas, que formaban colonias alfa-hemolíticas de $0,5 \mathrm{~mm}$, grises, lisas, con bordes enteros, catalasa negativas que aglutinaban frente a antisuero grupo D de Lancefied y no lo hacían frente a antisuero específico de $S$. pneumoniae. El microorganismo aislado fue identificado como "Streptococcus suis 2" mediante el sistema semiautomatizado de pruebas bioquímicas miniaturizadas API 20 Strepto (bioMérieux). Se realizaron otras pruebas para su diferenciación con otros cocos grampositivos en cadena no betahemolíticos, como fueron la ausencia de crecimiento en medio con $\mathrm{ClNa}$ al $6,5 \%$, la resistencia a la optoquina, la negatividad de la reacción bilis-esculina y la no producción de ácido a partir de la melobiosa. Mediante técnicas de aglutinación y coaglutinación se confirmó la presencia de $S$. suis serotipo 2.

Se mantuvo el tratamiento empírico en base a los resultados del antibiograma que mostró sensibilidad a penicilina, cefotaxi- ma, vancomicina y levofloxacino. Una semana más tarde el paciente fue dado de alta asintomático, sin secuelas neurológicas. No había evidencia de hipoacusia de percepción en la audiometría basal ni en la que se efectuó a los 6 meses.

Discusión: S. suis es un microorganismo causante de meningitis y otras infecciones en el ganado porcino. Según la composición antigénica de la pared celular $S$. suis aglutina con antisueros de los grupos R, S, o T de Lancefied, pero los que aglutinan frente al grupo $\mathrm{R}$ pueden hacerlo también frente al grupo $\mathrm{D}$, como ocurrió en el caso expuesto, debido a una reacción cruzada. Según la composición antigénica capsular se conocen más de 30 serotipos diferentes de $S$. suis, siendo el serotipo 2 el responsable de la mayoría de las infecciones en el hombre.

Las infecciones por $S$. suis en humanos producen en la mayoría de los casos meningitis purulenta. Otras infecciones pueden incluir neumonía, artritis, diarreas, endoftalmitis, bacteriemia, endocarditis, púrpura fulminante y rabdomiolisis $(5,7)$. La vía de acceso del patógeno puede ser cutánea (a través de laceraciones en la piel), respiratoria o digestiva. En el caso aportado el comienzo de la clínica en forma de gastroenteritis aguda hace muy probable la vía digestiva como puerta de entrada. Aunque la mortalidad de la meningitis es baja (7-9\%), pueden producirse secuelas auditivas en el 40-60\% de los casos. La hipoacusia de percepción podría estar en relación con una laberintitis supurativa. Es posible que la dexametasona reduzca la incidencia de esta complicación $(1,5)$.

Los casos de meningitis por $\mathrm{S}$. suis se han producido en individuos con exposición laboral a ganado porcino. La mayoría de los individuos afectados eran inmunocompetentes. En nuestro caso el paciente estaba esplenectomizado. De los cinco episodios descritos en la literatura de meningitis por $S$. suis en individuos esplenectomizados, tres fallecieron de manera fulminante (7). Algunos autores han recomendado que los pacientes con este factor de riesgo eviten trabajar en puestos laborales con riesgo de contacto elevado (8).

\section{Agradecimiento}

A la Doctora Carmen Terradas, del Departamento de Sanidad Animal de la Facultad de Veterinaria de Córdoba, por su inestimable ayuda en la identificación del patógeno.

\section{E. de la Hoz Adame, F. de la Rubia Martín, B. Domínguez Fuentes, D. García Gil}

Servicio de Medicina Interna. Hospital Universitario Puerto Real. Servicio de Microbiología. Hospital Santa María del Puerto. El Puerto de Santa María. Cádiz.

1. Geffner DE, Moreno R, Campillo MS, Pardo FJ, Gómez A, Martínez MD. Meningitis por Streptococcus suis. An Med Interna (Madrid) 2001; 18: 317-318.

2. Martínez P, Justado JJ, Gómez J, Solis J. Sacroileitis por Streptococcus suis tipo II. An Med Interna (Madrid) 1994; 11: 309.

3. Halaby T, Hoitsma E, Hupperts R, Spanjaard L, Luirink M, Jacobs J. Streptococcus suis meningitis, a poacher'risk. Eur J Clin Microbiol Infect Dis 2000; 19: 943-945.

4. Kopic J, Tomic Paradzic M, Pandak N. Streptococcus suis infeccion as a cause of severe illness: 2 cases from Croatia. Scand J Infect Dis 2002; 34: 683-709.

5. Asensi JM, Asenci V, Arias M, Moreno A, Perez F, Navarro R. Meningitis por Streptococcus suis A propósito de dos casos y revisión de la literatura. Enferm Infecc Microbiol Clin 2001; 19: 186-8.

6. Juncal AR, Pardo F, Rodríguez I, Pérez del Molino ML. Meningitis por Streptococcus suis. Enferm Infecc Microbiol Clin 1997; 15: 120-1.

7. Gallagher F. Streptococcus Infección and splenectomy. The Lancet 2001; 357: 1129-1130.

8. Watkins EJ, Brooksby P, Scheweiger MS, Enright SM. Septicaemia in pig-farm-worker. The Lancet 2001; 357: 38. 